\title{
Effect of monosodium glutamate on liver of pregnant rats and their fetuses (Histological and histochemical studies)
}

\author{
Eid F. A. ${ }^{1}$, Abu Elnaga N.A. ${ }^{1}$, Sarhan M. ${ }^{2}$, Mansour H. ${ }^{1}$ \\ 1- Zoology Department, Faculty of Science, Al-Azhar University, Cairo (Girls branch) \\ 2- Zoology Department, Faculty of Science, Al-Azhar University, Assuit
}

\begin{abstract}
Background: monosodium glutamate (MSG) is a widely used flavor enhancer and stabilizer in readymade or packaged foods. The excessive use of MSG increases the oxidative stress in the different body systems and causes teratogenic effects on fetuses of mothers treated with it in the gestational periods. Aim of the work: this study investigated effects of MSG on maternal and fetal liver tissue. Material and Methods: the present work was carried out on fifty mature pregnant Albino rats (Weight $200 \pm 20 \mathrm{~g}$ ) and six male rats in the reproductive age (Older than 60 days). The first group was served as the control group. The remnant pregnant rats were categorized into two sub- groups. Animals of the $1^{\text {st }}$ sub group were dissected on day $15^{\text {th }}$ of gestation $(\mathbf{C 1 5})$ and the second was dissected on day $19^{\text {th }}(\mathbf{C 1 9})$ of gestation. The second group was administrated monosodium glutamate daily with the dose of $7 \mathrm{~g} / 10 \mathrm{~mL} / \mathrm{kg}$ body weight from the $9^{\text {th }}$ to $14^{\text {th }}$ of gestation. Then the pregnant mothers were categorized into two sub- groups, the first was dissected on the $15^{\text {th }}$ day (G15) and the second on the $19^{\text {th }}$ day $($ G19) of gestation. The pregnant mothers were dissected after anesthesia which was performed by Halothane produced by Pharco. Comp. The uterine horns were removed from the surrounding fats then fetuses were removed from the surrounding amniotic membranes. Histopathological and histochemical studies were done on the maternal and fetal liver tissue through hematoxylin-eosin stain and Feulgen reaction. Results: numerous degenerative changes were detected in both maternal and fetal liver tissues of G15 and G19 groups. These changes included: vacuolation in hepatocytes, degenerative and necrotic areas and atrophied size of hepatocytes with pyknotic nuclei. These changes were observed in the centrolobular zones and the portal zones. Conclusions: this study showed that short-term MSG exposure in the gestational periods caused several histological and histochemical changes in the maternal and fetal liver tissues. These findings should be re-evaluated in additional long-term studies.
\end{abstract}

\section{Introduction}

The fetus is very sensitive to any little changes inside the mother body. The responsible mechanism for these alterations is limited not only by ethical reasons, but also by the multiplicity of uncontrolled variables ${ }^{(1)}$. Monosodium Glutamate (MSG) is one of the world's most extensively used food additives which were ingested as part of commercially processed foods. As a flavor enhancer MSG increases the sapidity of food ${ }^{(2)}$. Glutamate is the excitatory neurotransmitter in the mammalian central nervous system (CNS) and it plays an important role in both physiological and pathological processes. Chemically, MSG is a hydrated sodium salt of L-glutamic acid which is naturally found in humans and other higher animals as a neurotransmitter substance for brain functions. Toxicity of MSG is due to its toxicokinetics and tissue specific toxicodynamics in the body ${ }^{(3)}$. Neonatal administration of MSG provided a model of obesity with impaired glucose tolerance and insulin resistance led to concerns about obesity in humans using MSG in food. More hypotheses have proposed the mechanisms of MSG influence on metabolism. The potential link between MSG and obesity included the MSG effect on energy disrupting the hypothalamic signaling cascade of leptin action ${ }^{(4)}$. In male Swiss Albino mice subcutaneous administration of MSG at a dose of $2 \mathrm{mg} / \mathrm{g}$ during the perinatal period at the $2^{\text {nd }} 4^{\text {th }}, 6^{\text {th }}, 8^{\text {th }}$ and $10^{\text {th }}$ days of life led to increase the number of the pachytene stage of primary spermatocyte at the $75^{\text {th }}$ day of life compared to the controls. $4 \mathrm{mg} / \mathrm{gof}$ MSG administered to newborn rats resulted in decreased weight of pituitary glands and testes and lowered testosterone level in 4 months old sexually mature male rats . In female Swiss Albino mice, subcutaneous injection of MSG $(2 \mathrm{mg} / \mathrm{g})$ at the same perinatal periods $\left(2^{\text {td }}, 4^{\text {th }}, 6^{\text {th }}, 8^{\text {th }}\right.$ and $10^{\text {th }}$ days of life) led to increased number of the primary follicles without any increase in number of Graffian follicles in the ovarian tissue on day 75 of life ${ }^{(5)}$ Histological examination of MSG-treated rats treated with $0.6 \mathrm{mg} / \mathrm{g}$ and $1.6 \mathrm{mg} / \mathrm{g}$ for 28 days showed altered liver architecture, congestion in the central vein, dilated sinusoids and atrophied nuclei of the hepatocytes nuclei and the liver tissue had inflammatory cells, fluid retention, bleeding, congestion and necrosis ${ }^{(6)}$. MSG may increase the palatability of food by disrupting the hypothalamic signaling cascade of leptin action. The decreased adipose tissue activity, increased adiposities and liver lipogenesis rate in MSG induced obese animals were detected by Calis et $a l .{ }^{(7)}$. Histochemical studies in adult Wistar rats received MSG (2 $\mathrm{g} / \mathrm{kg}$ for 7 days) showed that glutamate had some deleterious effects on the liver (8). 
There was a significant increase in liver weight of rats treated with $70 \mathrm{mg} / \mathrm{kg}$ of MSG for 30 days which could be attributed to increased activity of inflammatory agents and oxidative damage that might led to inflammation of liver tissue. After administration of MSG to rats (40 $\mathrm{mg} / \mathrm{kg}, 9$ days) there was a significant increase in the body weight which may be due to obesity. MSG- obesity link led to alteration of regulatory mechanism that affect fat metabolism (9). Bhattacharya et al. (10), Kumbhare et al. (11) detected many histological changes in the hepatocytes and their nuclei with presence of inflammatory cells around the central veins in adult Wister rats after treatment with MSG(3 and 6 $\mathrm{mg} / \mathrm{Kg}$ body weigh daily for 45 days). Deleterious changes in the liver tissue of rats treated with MSG (3 and $6 \mathrm{mg} / \mathrm{Kg}$ body weigh daily for 45 days).

\section{2 -Material and methods}

The present work was carried out on fifty mature pregnant Albino rats (Weight $200 \pm 20 \mathrm{~g}$ ) and six male rats in the reproductive age (Older than 60 days). They were obtained from $\mathrm{El}$ Rammed Medical Hospital, Cairo. The experimental animals were randomly categorized into four groups. The normal and treated rats were individually settled in stainless steel cages with regular cages about $43 \mathrm{~L} \times 30 \mathrm{~W} \times 20 \mathrm{H} \mathrm{cm}^{3}$. The animals were kept in equal day-night cycle $(12 \mathrm{~L}$ : $12 \mathrm{D})$ at room temperature $22 \pm 2{ }^{\circ} \mathrm{C}$. Rats of the control group as well as other treated groups were given free access standard chow and water $a d$ libitum. The rats were stayed for 2 weeks for adaptation then the experiment was started. The technical standards and international guidelines for research on animals were followed ${ }^{(\mathbf{1 2})}$.

Chemicals used, dosage and treatment periods:

Monosodium glutamate (MSG) with purity 99\% was purchased from Sigma Chemical Company (USA). It was in the form of small pellets and given orally by the gastric tube with a dose of $7 \mathrm{~g} / 10 \mathrm{~mL} / \mathrm{kg}$ body weight. The doses were selected after detecting acute LD50 value which was found to be $16.60 \mathrm{~g} / \mathrm{kg}$ (oral, rat) .The treatment was given for 6 days from $9^{\text {th }}$ to $14^{\text {th }}$ during the gestational period ${ }^{(13) \text {. }}$

\section{Mating:}

- Female rats were marked and housed six per cage. Vaginal smears were recorded daily at the morning. The female completed at least two consecutive estrus cycles before use.

- Each two females in pro estrus or estrus periods were transferred to the cage of one fertile male. In the next morning, the females were examined. The presence of vaginal plug or sperms in the vaginal smear was referred to successful the mating and this considered as the zero day of pregnancy.

- The gestation period in the rats is 21 days. In the present study, the pregnant mothers were followed up by gradual increase in the body weight, a sudden decrease of their weight and /or presence of blood drops were considered as sings of abortion. The females who didn't mate during two estrus cycles were excluded from the study ${ }^{(14) .}$

Animals and the experimental design: the pregnant rats were randomly assigned to four groups:

1) The first group (Control group): the pregnant rats were categorized into two sub- groups. Animals of the $1^{\text {st }}$ sub group were dissected on the $15^{\text {th }}$ day $(\mathbf{C 1 5})$ and rats of the second sub group were dissected on the $19^{\text {th }}$ day (C19) of gestation.

2- The second group was administrated monosodium glutamate daily with the dose of $7 \mathrm{~g} / 10 \mathrm{~mL} / \mathrm{kg}$ body weight on days $9^{\text {th }}$ to $14^{\text {th }}$ of gestation. Then the pregnant mothers were categorized into two sub- groups, the first was dissected on the $15^{\text {th }}$ day (G15) and the second on the $19^{\text {th }}$ day $($ G19) of gestation.

\section{Determination of the estrus cycle stages:}

1- This technique involved insertion of a saline solution drop into the vagina by a Pasteur pipette, no deeper than $1 \mathrm{~cm}$. Then the drop of saline solution was aspirated and examined under the microscope.

2- The proestrus stage was appeared as nucleated epithelial cells, but the estrus stage was observed as cornified epithelial cells. The females in this stage were ready for mating.

3- The basophilic cells and a lot of mucus were refried to meet estrus stage and the leukocytes cells were refried to diestrus stage which indicated not ready for mating ${ }^{(14)}$.

\section{Histological and histochemical techniques:}

The pregnant mothers were dissected after anesthesia which was performed by Halothane produced by Pharco Comp. The uterine horns were removed from the surrounding fats and then fetuses were removed.

In the present study, the specimens of the liver tissues of pregnant rats and their fetuses were taken - Specimens were fixed in $10 \%$ neutral buffer formol for the histological technique and others were fixed in Carnoys' fluid for the histochemical technique. Then they were washed, dehydrated in ascending grades of alcohol, cleared in xylene and embedded in paraffin wax. The blocks of wax were 
cut $5 \mu$ in thickness and mounted on glass slides. For histological examinations, some specimens were stained with hematoxylin and eosin stain according to the method of Drury and Wallington (15). In another slides, the optical density of DNA was recorded by image analysis after using Feulgen reaction ${ }^{(16)}$.

\section{Statistical analysis:}

All data were presented as mean $\pm \mathrm{SD}$. Values of $p<0.05$ were considered statistically significant. The data were analyzed by using $\mathrm{T}$ test in SPSS 17.0 software (Excel program). The image analysis for optical density of DNA Feulgen reaction occurred by Bel micro program analyzer (ver. 2.3 / 01.04.2007)

\section{Laboratory facilities:}

The facilities including animal housing, histological and histochemical analysis was performed in the Department of Zoology, Faculty of Science, Al-Azhar University (Girls branch).

\section{Results}

The histopathological and histochemical

observations :

Liver of pregnant rats:-

Microscopic examination of the liver tissue of the control group showed normal structure and appearance of hepatic tissue. Typical hepatic lobules were present as cords of hepatocytes radiating from the central vein and separated by the hepatic sinusoids. The hepatocytes have eosinophilic cytoplasm, large rounded nuclei and prominent nucleoli. The sinusoids are lined with endothelial cells and scattered phagocytic Kupffer cells. A typical portal tract is containing branches of the hepatic portal vein, hepatic artery and bile ducts. Thin collagen fibers were supporting walls of hepatocytes, sinusoidal spaces and blood vessels (Figs. 1, 3, 5, 7).

Liver tissue of pregnant rats of group G15 showed highly dilated and congested sinosodial spaces, pyknotic nuclei of hepatocyte , hemolyzed blood cells inside the congested central veins and corrugated and delaminated endothelial lining of them (Figs. 2,4). Liver tissue of pregnant rats of group G19 showed numerous necrotic areas, hemorrhagic areas, congested sinusoidal spaces, highly dilated walls of the congested central veins which contained hemolyzed blood cells, numerous pyknotic or karyolitic nuclei of hepatocytes, aggregated lymphocytes and fibroblasts in the portal areas, highly distorted walls of the bile ducts and increased Kupffer cells (Figs. 6,8 ).

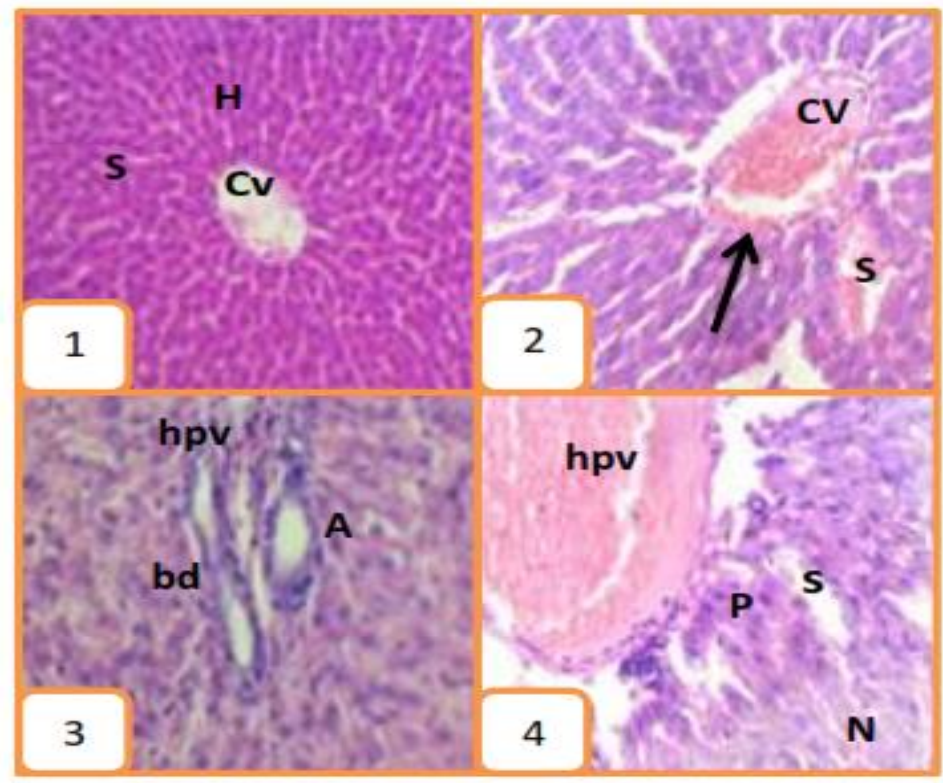

Figs.1-4: showing photomicrographs of liver tissues of C15 and $\mathbf{G 1 5}$ groups stained with hematoxylin and eosin. Figs. 1, 2 : photomicrographs showing normal structure of liver tissue of the control pregnant rat . Notice the central vein $(\mathrm{cv})$, cords of hepatocytes $(\mathrm{H})$ and blood sinusoids (s), branch of the hepatic portal vein (hpv) ,branch of the hepatic artery (A) and bile ducts (bd). Figs. 3, 4 : photomicrographs of maternal liver tissue of group G15 showing highly dialated and congested sinosodial spaces (s) pyknotic nuclei of hepatocytes(p), hemolysed blood cells inside the congested central vein $(\mathrm{Cv})$ with ruptured, corrugated and delaminated endothelial lining it $(\downarrow)$, walls of the hepatic portal veins (hpv) are lymphocytic infiltration in the portal area with numerous necrotic areas (N). ( $\mathbf{H} \& \mathbf{E} 1 \mathbf{1} 100 \& 2$ $4 \times 200$ ) 


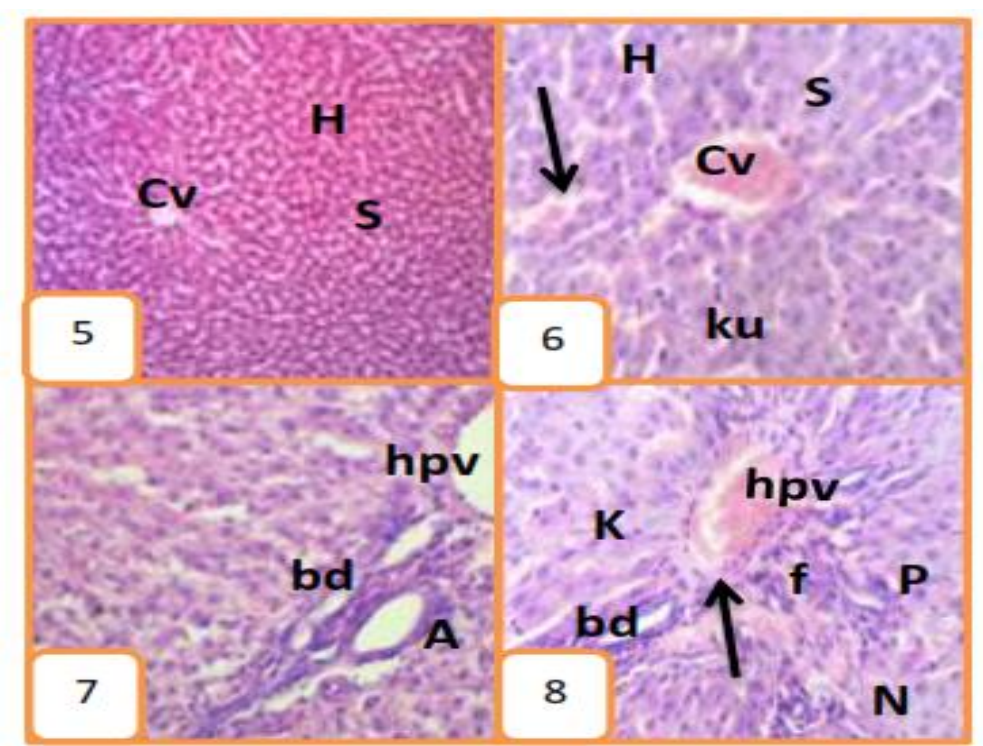

Figs. 5- 8: photomicrographs showing maternal liver tissue of $\mathbf{C 1 9}$ and $\mathbf{G 1 9}$ groups stained with hematoxylin and eosin. Figs. 5, 7: showing liver tissue of the control mother C19. Notice: the central and portal areas which contain branch of the central vein (cv), cords of hepatocytes $(\mathrm{H})$, sinusoidal spaces (s), the hepatic portal vein (hpv), branch of the hepatic artery (A) and bile ducts (bd). Figs. 6, 8: showing maternal liver tissue of group G19 with numerous necrotic areas $(\mathrm{N})$, hemorrhagic areas $(\uparrow)$, congested sinusoidal spaces (s), highly dilated and congested wall of the central vein (CV) which contains hemolysed blood cells , numerous pyknotic $(\mathrm{p})$ or karyolytic $(\mathrm{k})$ nuclei of hepatocytes, aggregated lymphocytes and fibroblasts in the portal area (f),highly distorted walls of the bile ducts (bd) and increased Kupffer cells ( ku). (H\&E X 200)

\section{Fetal liver tissue}

Fetal liver tissue of the control groups $(\mathbf{C 1 5}$, C19) showed normal structure of the central vein, cords of hepatocytes, sinusoidal spaces and numerous megakaryocytes with thin bundles of collagen fibres supporting the hepatocytes, sinusoidal spaces and walls of the central veins (Figs. 9 , 13, 14 ). Fetal liver tissue of group G15 showed highly dilated and ruptured wall of the central vein, numerous necrotic areas, congested blood sinusoids which contain hemolysed blood cells , numerous pyknotic nuclei of hepatocytes, degenerated areas, lots of nucleated RBCs and faintly stained nuclei of megakaryocytes (Figs. 10-12 ). Fetal liver tissue of group G19 showed numerous necrotic areas which contained degenerated hepatocytes, lots of nucleated RBSs (micronuclei), highly dilated wall of the central vein, highly dilated and congested blood sinusoids which contained hemolysed blood cells and numerous pyknotic nuclei in hepatocytes (Figs. 15,16 ).

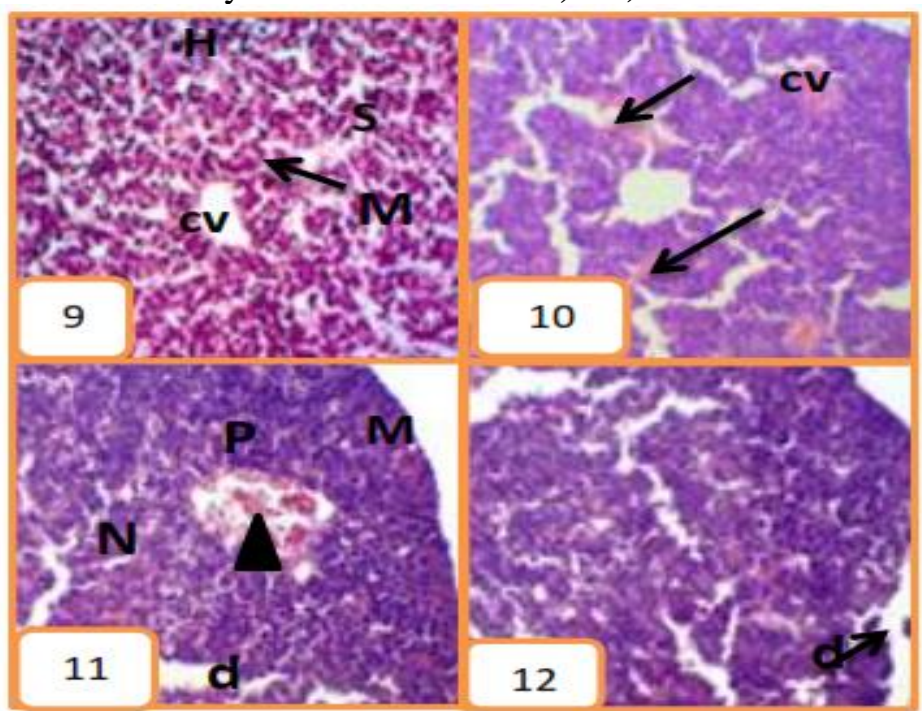

Figs.9-12 : showing photomicrographs of fetal liver tissue of the control (C15) and treated group (G15) stained with hematoxylin and eosin. Fig. 9: showing normal structure of fetal liver tissue of group C15. Notice: the central vein (cv) surrounded by the hepatocytes $(\mathrm{H})$ and blood sinusoids(s) in between them. Figs. 10-12 : showing fetal liver tissue of group G15 with highly dilated walls of the central veins (CV), numerous necrotic areas $(\mathrm{N})$, dilated blood sinusoids which contain hemolysed blood cells $(\rightarrow)$, numerous pyknotic nuclei of 


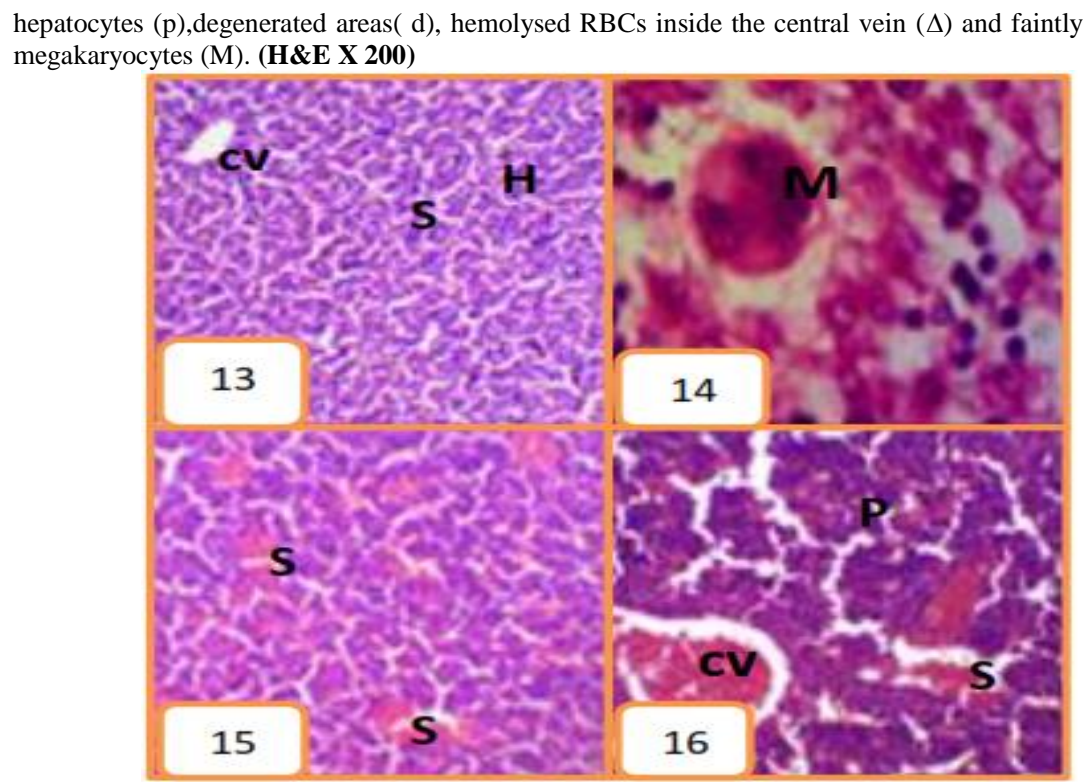

Figs. 13-16 : showing photomicrographs of fetal liver tissue of C19 and G19 groups stained with hematoxylin and eosin. Figs. 13,14 : showing normal structure of fetal liver tissue of group C19 with normal hepatocytes $(\mathrm{H})$ surround the central vein (cv), blood sinusoids(s) in between them and megakaryocytes (m). Figs. 15,16 : showing fetal liver tissue of group G19 with highly dilated wall of the congested central veins (CV), hemolysed RBCs inside the central vein, numerous necrotic areas $(\mathrm{N})$, dilated blood sinusoids which contain hemolysed blood cells (s), numerous pyknotic nuclei of hepatocytes (p) and degenerated areas( d). (H\&E 13,15X 100\& 16X 200\& 14x 400)

of rats of group $\mathbf{G 1 9}$ when compared to the control group. Table 1 and figure 18 showed the optical density values (Pixel) of DNA materials in the fetal liver tissue of the different experimental groups. The mean value of DNA materials in the fetal liver tissue of the control group $\mathbf{C 1 5}$ recorded 146.83 \pm 63.43 pixel. While, DNA materials value of group G15 reached $77.04 \pm 35.28$ Pixel. DNA materials in the liver tissue of the control group C19 reached $138.49 \pm 60.08$ Pixel. While, DNA materials value of group G19 reached 81.97 \pm 36.57 . The percentage of change of DNA materials was $47.51 \%$ in the liver tissue of group G15 and reduced to $-40.81 \%$ in group G19.

\section{The histochemical studies of the liver tissue}

Table 1 and figure 17 showed measurements of the optical density values (Pixel) of DNA materials in the liver tissue of mothers in the different experimental groups. The mean value of normal DNA content recorded $143.14 \pm 61.96$ pixel in the liver tissue of rat of the control group C15, but it reached $51.29 \pm 23.07$ pixel in G15 group. DNA materials of group $\mathbf{C 1 9}$ recorded $148.81 \pm 64.38$ pixel. This value decreased in group G19 to $53.81 \pm 27.7$ pixel. The percentage of change of DNA content in the liver tissue reduced to $-64.16 \%$ in group $\mathbf{G 1 5}$ and $63.83 \%$ in the liver

\begin{tabular}{|l|c|c|c|c|}
\hline Parameters & C15 & G15 & C19 & G19 \\
\hline & & $51.29 * *$ & & $53.81 * *$ \\
Mother liver & 143.14 & \pm 23.07 & 148.81 & \pm 27.7 \\
& \pm 61.96 & -64.16 & \pm 64.38 & -63.83 \\
\hline & & $77.04 * *$ & & $81.97 *$ \\
Fetal liver & 146.83 & \pm 35.28 & 138.49 & \pm 36.57 \\
\hline
\end{tabular}

Table 1: showing the optical density values (Pixel) of DNA materials of maternal and fetal liver tissues of all groups

- Each value represented the mean and \pm standard deviation (SD).

- The values are considered significant at $* \mathrm{P} \leq 0.05$ and highly significant at $* * \mathrm{P} \leq 0.01$. 
Compared to the control group.

C15 and C19, control groups, G15 and G19, administrated MSG and dissected on days $15^{\text {th }}$ and $19^{\text {th }}$ respectively.

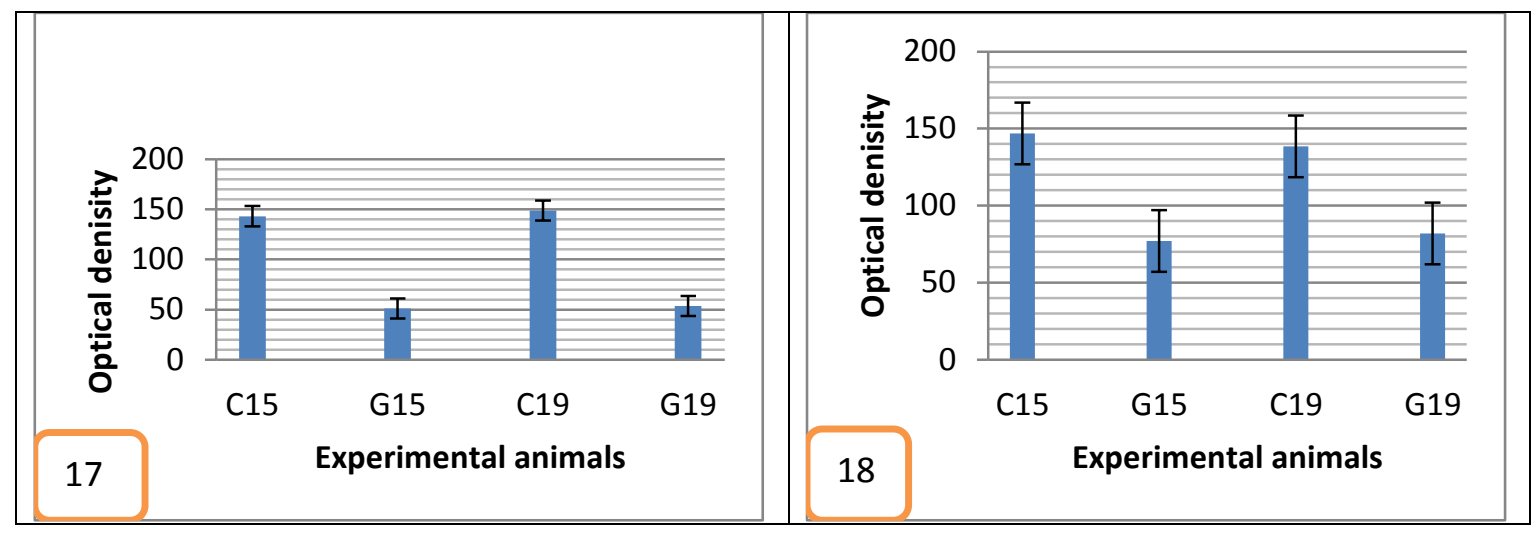

Figs.18,19:Histograms showing the optical density values (Pixel) of DNA materials in the maternal and fetal liver tissues of all groups

\section{Discussion}

\section{Liver of the pregnant rats:-}

Many degenerative changes were observed in liver tissue of mothers treated with MSG and dissected on days $15^{\text {th }}$ and $19^{\text {th }}$ of gestation $(\mathbf{G 1 5}$, G19) and these changes included: highly distorted central veins, aggregated lymphocytes, with numerous cytoplasmic and nuclear changes in the hepatocytes and distorted blood vessels. These findings are similar to those of Shrestha et al. ${ }^{(6)}$ and Kumbhare et al. (11) who observed mononuclear infiltration in the portal areas with neutrophils aggregation They detected highly affected central and portal veins with their endothelial lining post MSG treatment. In the present results, experimental animals showed aggregated lymphocytes and fibroblasts in the central and portal areas, hyperplasia in the bile ducts, increased Kupffer cells with blood hemolysis inside the blood vessels. These results are agreement with results of Kumbhare et al. ${ }^{(11)}$ who observed mononuclear infiltration in the portal areas with neutrophils aggregation in rats treated with monosodium glutamate. They added that migration of leucocytes towards the area of inflammation is known as chemo taxis and can be explained the role of leucocytes in general and lymphocytes in particular as a prominent response of body tissue facing any injurious impacts. Also, the present results are in agreement with those of Kumbhare et al. ${ }^{(11)}$ who observed vacuolated cytoplasm and condensed nuclei in most hepatocytes. The presence of these vacuoles may due to presence of fat droplets which represents the response of hepatocytes to the ingestion of monosodium glutamate. Similar observations were reported by Al-Mosaibih ${ }^{(17)}$. In the present study, liver of mothers treated with monosodium glutamate showed lots of necrotic and hemorrhagic areas. Similar findings were observed by AlMosaibih ${ }^{(17)}$ who found that MSG treated mice (30mg/ $\mathrm{kg}$ of MSG for continuous 4 weeks ) showed distorted histological architecture of hepatic cords, highly affected blood vessels with increased signs of apoptotic cell death ${ }^{(10)}$. The present findings showed highly widened sinusoidal spaces, lots of hemorrhagic and fibrotic areas with congested the central and the portal veins. These findings are similar to those of Shrestha et al. ${ }^{(6)}$ who found dilated sinusoidal spaces with erosion in the endothelial lining of blood sinusoids. Bhattacharya et al. ${ }^{(10)}$ and Kumbhare et al. ${ }^{(11)}$ found highly affected hepatic cords with increased Kupffer cells. Ciobanu et al. ${ }^{(\mathbf{1 8})}$ found acute fatty liver and elevated liver enzymes in the maternal blood which was associated with fetal death and several changes such as severe hypoglycemia, hyperuricemia, markedly elevated transaminases and renal impairment with elevated creatinine. All these factors may lead to damage liver cells of mothers due to increased number of fetal death like in the present study. So, the damage observed in the maternal liver may due to two factors, MSG and complications due to early fetal death. The present study showed reduced percentage of change of DNA content in the maternal liver tissue of groups G15 and G19 which reached $-64.16 \%$ and $63.83 \%$ respectively . Al-Mosaibih (17) attributed the pathological changes which were observed post MSG treatment to the oxidative stress of it. This can be explained by the fact that 
MSG led to generation of oxygen derived free radicals and related reactive oxygen species (ROS). These substances are dangerous for the biological systems as they react with DNA, proteins and lipids then lead to cellular damage.

\section{The fetal liver tissue:}

Fetal liver tissue of $\mathbf{G 1 5}$ and $\mathbf{G 1 9}$ groups showed highly dilated and ruptured wall of the central veins. These results are similar to those of Calis $\boldsymbol{e t} \boldsymbol{a l}$. (7) who found disrupted hepatic cords, lymphocytic infiltration in the central areas with numerous necrotic, degenerated and hemorrhagic areas as a response of oral MSG in adult Wister rats. The present findings showed signs of hemolysis in highly dilated and congested blood sinusoids. These results are similar to those of Kumbhare et al. ${ }^{(11)}$ who examined liver cross sections of $14^{\text {th }}$ days MSG treated chick embryos and observed hemorrhagic areas and congested blood vessels with dilated blood sinusoids, vacuolated hepatocytes, lymphocytic inflammation around the central veins and hypertrophied nuclei; these changes may be may due to hepatotoxic effect of MSG on the liver tissue In the present study, there were lots of nucleated RBCs and faintly stained nuclei of megakaryocytes .These results are similar to those of Al-Qudsi and Al-Jahdali ${ }^{(19)}$ who examined fetal liver sections on days $7^{\text {th }}, 10^{\text {th }}$ and $14^{\text {th }}$ of gestation treated with MSG and detected no clear plasma membranes in most hepatocytes with increased lipid droplets and phagocytic cells in the blood sinusoids that had detached lining epithelial cells. The present results showed numerous necrotic and degenerated areas and these findings are similar to those of Calis et al. ${ }^{(7)}$ who detected numerous degenerated and necrotic areas in the liver tissue after injection of rats with a single dose of MSG ( $2 \mathrm{~g} / \mathrm{kg}, 3$ days). The present study showed signs of pyknosis in nuclei of hepatocytes of G15 and G19 groups. These results are similar to those of Al-Qudsi and Al-Jahdali ${ }^{(18)}$ who observed atrophied nuclei of the hepatocytes some of them showed pyknosis and others showed karyolysis . Results of the present work showed that the percentage of change of DNA materials decreased about $-47.51 \%$ in the liver tissue of $\mathbf{G 1 5}$ group and $-40.81 \%$ in $\mathbf{G 1 9}$ group. Al-Mosaibih ${ }^{(17)}$ and Oladipo et al. (20) attributed these changes after MSG administration to the oxidative stress. Also, Shredah ${ }^{(21)}$ found that MSG increased DNA damage and fragmentation. They added that in the comet assay, MSG additive caused DNA damage at all concentrations in isolated human lymphocytes after $1 \mathrm{~h}$ in vitro exposure.

\section{References}

1- Carlson B M (2009): Human Embryology and Developmental Biology. $4^{\text {th }}$ ed. Mosby El sevier, Philadelphia. P. 312.

2- Mondal T, Bag I et al. (2018): Two way controls of apoptotic regulators consign . doi.org/10.1371/journal.pone.0190548.

3- Jinap S and Hajeb P (2010): Glutamate. Its applications in food and contribution to health. Appetite, 55(1):1-10.

4- He K, Du S et al. (2011): Consumption of monosodium glutamate in relation to incidence of overweight in Chinese adults: China health and nutrition survey (CHNS). The American Journal of Clinical Nutrition, 93(6): 1328-1336.

5- Das R S and Ghosh S K (2011): Longterm effects in ovaries of the adult mice following exposure to monosodium glutamate during neonatal life- A histological study. Nepal Medical College Journal, 13(2): 77-83.

6- Shrestha S, Jha C B, Laida B K and Yadav $P$ (2018): Effects of monosodium glutamate on liver tissue of Wistar Albino rats: histological and biochemical study. International Journal of Therapeutic Applications, 35: 68-73.

7- Calis I U, Cosan D T et al. (2016): The Effects of monosodium glutamate and tannic acid on adult rats. Iran. Red. Crescent Med. J., 18(10):1-7.

8- Nandan P, Nayanatara A K, Poojary $R$ , Bhagyalakshmi $K$, Nirupama $M$ and Kini R D (2018): Protective role of coadministration of vitamin $\mathrm{D}$ in monosodium glutamate induced obesity in female rats .J. National Medic. Assoc., 110(1): 98-102.

9- Kawakita T ,Chiaki S, Shigeru S , Masahiro $T$ and Shizuko $Y$ (2015): Monosodium glutamate. Ullmann's Encyclopedia of Industrial Chemistry. doi.org/10.1002/14356007.a16_711.pub2.

10- Bhattacharya T, Bhakta A and Ghosh S K (2011): Long term effect of monosodium glutamate in liver of albino mice after neonatal exposure. Nepal Medical College Journal, 13(1): 11-16.

11- Kumbhare V, Gajbe U , Singh B R ; Reddy A K and Shukla S (2015): Histological and histochmical changes in liver of adult rats treated with monosodium glutamate: a light microscopic study. World Journal Of Pharmacy and Pharmaceutical Sciences, 4 (04): 898-911. 
12- Roy George K, Shibija N G and Malini N A (2013): Monosodium glutamate (MSG) induced developmental dysfunction in female albino rats (Rattus norvegicus). An International Journal of Life Sciences, 8(1): 73-76.

13- Nayanatara A K , Vinodini $\mathbf{N}$ A , Ahemed B , Ramaswamy C R , Shabarianth G and Ramesh $M$ (2008): Role of ascorbic acid in monosodium glutamate mediated effect on testicular weight, sperm morphology and sperm count in rat testis. Journal of Chinese Clinical Medicine, 3:1-5.

14- Abd Rabu M (2013): Modulation of radiation injury in pregnant rats by bone marrow transplantation. M.Sc. Zoology Department, Faculty of Science, Al-Azhar University, Cairo.

15- Drury $R$ and Wallington E (1967): Carlton's Histological Technique. $4^{\text {th }}$ ed., Oxford. Univ. Press, New York, p.432.
16- Drury $R$ and Wallington $E$ (1980): Carleton's Histological Technique, $4^{\text {th }}$ Ed. Oxford. Univ. Press, New York, Toronto.

17- Al-Mosaibih M A (2013): Effects of monosodium glutamate and acrylamide on the liver tissue of adult Wistar rat. Life Sci. J., 10(2): 35-42.

18- Ciobanu A M , Colibaba $S$, Cimpoca B , Peltecu G and Panaitescu A (2016) : Thrombocytopenia in pregnancy. Maedica (Buchar), 11(1): 55-60.

19- Al-Qudsi F and Al-Jahdali A (2012): Effect of monosodium glutamate on chick embryo development. J. Amer. Sci., 8(10): 499-509.

20- Oladipo I C, Adebayo E A and Kuye O $M$ (2015): Effects of monosodium glutamate in ovaries of female SpragueDawley rats. Int. J. Curr. Microbiol. App. Sci., 4(5): 737-745.

21- Shredah M T (2017): Molecular study to the effect of monosodium glutamate on rat gingiva. Tanta Dental J., 14(3): 155-163. 